Nordisk Museologi 200I • I-2, S. 4-II

\title{
DA FYRSTIKKFABRIKKEN BLE BYGGET
}

\author{
John Aage Gjestrum
}

En liten sensasjon var det i sommer da Terje Vegar Larsen kom innom arkivet på Stenberg med en gammel regnskapsprotokoll funnet på loftet til kårbygningen på garden Elton. Protokollen var fort av Jens Bjerknes (1835-1901) som var gardbruker og "propierter" på Elton ovenfor Raufoss.

Protokollen viser seg nemlig å inneholde "Fyrstik-Fabrikkens Regnskab" fra 27. juni 1873 til 15. september 1875. Dette dekker 38 sider. Lenger ut i protokollen er det ført regnskap for Elton for tidsrommet 1889-1900.

Jens Bjerknes var født i Fåberg, utdannet agronom, og kom til Vestre Toten i 1862 som bestyrer ved Lerudmyra interessentskap. Han kjøpte like etterpå garden Elton og var med i interessentskapet som i 1868 kjøpte Rødfossen gard. Dette selskapet bestod av forretningsfolk og bønder på Toten, Vardal og Gjøvik og drev særlig aktivt saga ved Rødfos Brug sammen med oppkjøp av skogeiendommer. I 1872 solgte interessentselskapet ved Jens Bjerknes Rødfossen til Martin Hveem på Smeby. Men allerede året etter selger Martin Hveem Rødfos gard til interessentselskapet Rødfos Fyrstikkfabrik ved Jens Bjerknes.

Ideen om å anlegge en fyrstikkfabrikk på Raufoss må altså ha kommet i 1873, og Jens Bjerknes som også var med i interessentselskapet fra 1868 er formann i styret for fyrstikkfabrikken og nokså sikkert en drivkraft bak prosjektet.
Mens interesssentselskapet fra 1868 hadde en forholdsvis liten aksjekapital fordelt på lokale hender, er aksjekapitalen i fyrstikkfabrikk-selskapet på hele 30.000 spesiedaler. En kapital som nok i hovedsak var hentet utenfor distriktet ettersom styremedlemmene utenom Bjerknes var hoffapoteker Hans S. Ditten, overrettssakfører Wilhelm Faye-Hansen, grosserer Gustav Christian Hellesen og hypotekbanksekretær Bernt Th. Paulsen.

Protokollen som har dukket opp følger aktiviteten med oppbyggingen av fabrikken fra høsten 1873 og fram til den var driftsklar to år etterpå.

Den første innførselen er fra 27. juni 1873: "Udlagt paa en Reise til Kristiania 5 Spd.", Jens Bjerknes hadde altså møtt styremedlemmene og investorene i Kristiania, der de sikkert hadde gjennomdrøftet hvordan oppbygningen av fabrikkanlegget skulle skje. Byggeprosessen startet nærmest umiddelbart, for den 17. juli utbetaler Bjerknes 6 spesidaler til Jens Knudsen "contant paa Gjøvik, paa Stenbrydningen". Den 22. august er Jens Knudsen igang "i Rødfossen" da han făr de neste 5 
spd., og fram til 7. mars 1874 fikk han totalt utbetalt 56 spd. Jens Knudsen brøt nokså sikkert gråsteinen til fabrikkmurene, og ut fra en omtrentlig beregning basert på lønnsnivået som er nevnt ellers i protokollen med 3 eller 4 ort pr. dag, kan vi regne med at Knudsen her fikk betalt for omlag 14 ukeverk. Det var $i$ et steinbrudd oppe ved Karsrudskogen steinen ble tatt, og sjøl om fyrstikkfabrikken er borte i dag, står de metertykke gråsteinsmurene ennå $\mathrm{i}$ en av fabrikkbygningene på Raufoss A/S. Ettersom det blir mye snakk om spesiedaler, ort og skilling i artikkelen, tar vi med at pengesystemet i Norge i 1816-1875 var bygd på at 1 spesiedaler rommet 5 ort, og at det i 1 ort var 24 skilling.

Det neste Jens Bjerknes gjør er å reise til Stavsmarken på Tretten i Gudbrandsdalen der han kjøper to hester. Han betaler dyrlege Plein 1 spd. "fordi han var behjelpelig ved Hestekjøbet", så han tok altså ingen sjanse på å få dårlige hester. Og hestekjøpet var heller ikke billig - den ene hesten ble kjøpt av J. Biessum fra Våga for 160 spd. og den andre fra Hans Stubberud i Fron for 135 spd. Jens Bjerknes kjøpte også med seletøy av A. Balling i Fåberg, og seinere kjøpte han en arbeidskjerre, en arbeidssele, en hjulslede og to "Træe Juel til en Vaagn" til hestene.

\section{Civilingeniør Adam Collin}

Ut fra regnskapsboka ser det ut til at Jens Bjerknes fikk assistanse fra og med l. september 1873 da navnet Collin dukker opp for første gang. Han ankommer til Raufoss fra Kristiania, ettersom det står i protokollen at han har "Medtaget fra Hansen" (fra overrettssakfører Faye-Hansen) et større pengebeløp. Samme dag fører Bjerknes 1 spd. til utgift "For denne Protokoll" og 8 skilling "For en Post- bog til Collin". Sivilingeniør Adam Collin var ansatt for å ha ledelsen av oppbygging og idriftssettelse av fabrikken og skulle vel bli bestyrer etter idriftssettelsen. Da firmaet meldte seg til handelsregisteret 25. januar 1875 er nemlig Collin kalt bestyrer. Regnskapsprotokollen viser at Collin ledet oppbygningen av fabrikken, og gjennom 1873, 1874 og våren 1875 er store og mindre beløp stadig utbetalt gjennom Collin. Den 14. april 1875 står imidlertid Collin nevnt for siste gang, og da har Bjerknes ikke bare skrevet "Collin" som oftest før, men "Udbetalt Hr. Ing. Collin contant 45 spd.” Regnskapsboka tyder altså på at Collin og Bjerknes skilte lag her, og da flere måneder før fabrikken var ferdig. Collin ble forresten seinere statsingeniør i Kristiansand.

\section{BYggematerialeR}

Allerede 3. september 1873 leser vi "Udlagt paa en Reise til Teterud, Sund, Gamme og Østgaardshagen i Anledning forskjellige Indkjøb 1 ort 18 sk." Den 12. september reiser han med "egen Hest fra Elton til Qvernum," og den 16. sept. betaler han C. Blaavarp og A. Qvernum vel 163 spd. for "82 Tylter Topstammer" og for 26 bjelker.

Dette var materialer som sannsynligvis skulle brukes til bjelkelag og takkonstruksjon på fabrikkbygningen. Muligens kom tømmeret fra Teiterud eller Sund og med C. Blaavarp og A. Overnum som mellommenn. Dette fordi tømmeret tydeligvis ble fløytet på fjorden. Den 17. sept. 1873 skriver Bjerknes: "Emil Vadet for at ro en Tømmergrime 1 Spd." Det var også lønn til Anton Blaavarp, Nikolai Blåvarp, Tommas Blaavarpeie, Mathias Qvernum, O. C. Qvernum og P. Fiskevolden. P. Fiskevolden fikk dessuten 60 skil- 
ling for å frakte lensen tilbake. Bjerknes la også ut 1 spd. ved sin "Nærværelse i Brøtningen."

En fast regel ved tømmerfløtning i Hunnselva var at fløterne hadde med seg rikelig med brennevin. En måtte stadig vekk ut i det iskalde vannet, og brennevinet var det eneste som kunne gi varme i krøppen. Og i regnskapsboka her kan vi også avlese dette på neste dag:

18. For Expres til Gjøvik —-18

-»-10 Potter, Brendevin 2-20

-»- Expres til Fiskevolden -2-

I tillegg er det ført 12 skilling som ekstra utgift til P. Fiskevolden. Det var blitt bygd demning ved Fiskevollen i 1871, og fløytinga startet derfor derfra.

Ellers kjøpes det stadig trematerialer - sagbord, to toms planke og tømmer. Den 29. april 1874 får Kristian Blåvarp utbetalt 102 spd, 1 ort 18 skilling for 97 tømmer og 5 skippund ulesket kalk og 7 tønner og 7 skippund lesket kalk. Dette var nokså sikkert kalk til gråsteinsmuringen. Denne handelen må vel også sees i sammenheng med reisen: "I Anledning forskjellige Indkjøb" som Bjerknes gjorde 3. september 1873, og der han besøkte Gamme og Østgaardshagen. Der var det jo kalkovner. I april 1875 fikk Anton P. Hagesveen gjennom Hans H. Gamengen utbetalt vel 10 spd. som restbetaling for kalk.

Teglstein ble kjøpt av Jens Mengshol (Ringsaker), først 10.000 stein i juli 1874, så 5.660 stein i juli 1875 . Denne steinen ble sikkert brukt til pipemuring, - i fabrikkbygningen 1874 og piper til arbeiderboligene i 1875.

Den nye hovedbygningen på Raufoss gård som skulle være bestyrerbolig og kontor, skal være bygget i 1874 . Det er vanskelig å presist identifisere den i regnskapsboka. Den 18. august i 1874 blir det imidlertid utbetalt nesten 400 spd. til J. Linnerud i Vardal for kjøpt tømmer. A. Prøven som er byggmester Andreas Prøven (1832-1905), fikk utbetalt 50 spd. 29. oktober. Noe av det siste som skjer i 1875 før hele anlegget skulle være ferdig er imidlertid kjøpet av 7 ruller tapet 25 . august 1875. Det er vanskelig å tenke seg at tapeten skulle brukes noe annet sted enn i hovedbygningen på Raufoss gård.

\section{Arbeiderboligene}

Regnskapsboka viser at fabrikkbygningen ble bygget først, og antakelig dernest den nye hovedbygningen på Raufoss gård. Men hvor skulle arbeiderne bo når fabrikken skulle starte opp?

Den 14. april 1875 har Jens Bjerknes imidlertid bokført en utgift på 160 spd: "Udbetalt Ole L. Undlien for den af ham kjøbte Stuebygning." Og samme dag: "Udbetalt Ole Undlien for kjørt 5 Las af Bygningen a 3 ort." To dager etterpå får Ole J. Fæstadsæter, Carl Buer, Nils Olsby, Peder A. Berjer, Johannes Vallesæter og Ole Alfstadsæter oppgjør "for, kjørt af den i Undlien kjøbte Bygning”.

I alt kjørte de 225 stokker og 4 lass med rajer. Byggmester Andreas Prøven fikk samme dag utbetalt 20 spd. Så han ledet nokså sikkert nedtakingen og gjenoppbyggingen av bygningen.

En måned senere, den 14. mai, utbetaler Bjerknes så 70 spd. til Ole J. Lae "paa den af ham kjøbte Bygning”. Ole J. Lae hadde garden Bjørnerud på Eina 1871-77, og den 19. juli får han $280 \mathrm{spd}$. "paa den kjøbte bygning”. Det første beløpet fikk han sikkert da avtalen om kjøp ble inngått, resten da bygningen ble levert.

Mens bygningen fra Undlien ble kjørt på 
et par dager av 6-7 av bøndene i Veståsen, finner en ingenting i regnskapsboka om kjøring av Bjørnerudbygningen. Derimot kan vi lese på den 23 . juli 1875 , altså 4 dager etter bygningen ble betalt: "Udbetalt Petter Olsen Elvepasser for Flødning 7 spd. 16 sk".

Her er det sjølsagt et viktig poeng at Undlienbygningen ble flyttet $\mathrm{i}$ april mens det var sledeføre, - Bjørnerudbygningen midt på sommeren. Sommerstid ville det vært en fryktelig jobb å kjøre alt bygningstømmeret på de elendige vegstubbene helt ute fra midt på Einafjorden og til Raufoss. Det er derfor neppe noen tvil om at bygningen ble fløytet, først på Einafjorden og så i Hunnselva.

Disse bygningene ble oppsatt slik de hadde vært, men påbygd svalgang i to etasjer etter ene langveggen. Bygningene stod så med svalgangen mot hverandre og gardsplassen imellom. Den ene bygningen hadde 6 leiligheter, de andre 8 , alle på ett rom og kjøkken. Hver leilighet hadde inngang fra svalgangen.

Noen år seinere ble det bygget en tredje arbeiderbolig vest for den nordre boligen. Alle ble revet omkring 1970 da det nye stålstøperiet ble bygd på Raufoss. Den søndre boligen ble imidlertid bevart og flyttet til friluftsmuseet på Stenberg. Det er den med 6 leiligheter og altså den minste av de to eldste. $\mathrm{Og}$ ettersom Undlienbygningen ble betalt med mindre enn halvparten av det Bjørnerudbygningen kostet, er det sannsynligvis Undlienbygningen som nå står på Stenberg.

\section{ArbeidsstokKen}

\section{VED BYGGEARBEIDENE}

Den 19. september 1873 utbetales lønningene for den første arbeidsuka i byggeanlegget. Da er hver enkelt nevnt, seinere vises det bare til lønningslister og samlet sum. Daglønna varierer mellom 3 og 4 ort, det vil si ei ukelønn på omkring $4 \mathrm{spd}$.

Det er 21 mann som får lønn: P. Mjøberg, Johan Tostenstuen, Andreas Bjørneløkken, Andreas Dragvold, Matias Farver, Peder Berger, Hans Nilsen, Løurits Pedersen, Ole Nilsen, Kristian Napstad, Martin Negaard, Hans C. Grøthaug, Hans Rogsvolden, Andreas Rødfosengen, Hans Rødfossen, Ole Rødfossen, Ole J. Pedersveen, Lars Madsen, Ole Murer, Hans Prøven og Andreas Prøven.

Fram til april 1875 utbetaler Collin lønningene over sin kasse der han får overført runde summer fra Bjerknes. Deretter er kostnadene pr. uke spesifisert. Alt tyder på at det i hele perioden arbeidet 20-30 mann i anlegget.

Fast lønningsdag er onsdager. Og det var bra å ha arbeid på anlegget. Lønningene lå godt over det dobbelte av hva en f.eks. tjente som arbeider i jordbruket.

Den eneste som er nevnt som murermester er "Murmester Skinstad" som i november 1874 får 42 spd. "paa Murarbeid contant." $\mathrm{Da}$ er imidlertid selve fabrikkbygningen antakelig allerede forlengst under tak. Etter det som har vært fortalt var det Lars Madsen (f. 1835) som var bas for gråsteinsmurerne. Ettersom han er med fra starten i bygget og også nevnes flere ganger underveis er antakelig det rett.

Alt tyder også på at Andreas Prøven ledet trearbeiderne, og han er også med gjennom hele byggeperioden. Blikkenslager er Martin Martinsen Grøthaugeie. A. Elstad og Anders Lisødegaard har tilsammen $15 \mathrm{spd}$. for "Tinarbeide". E. Narum gjør «Rørarbeide», mens "Bluncks Rørlæggere" blir skysset til Dal stasjon i Eidsvoll i august 1875 like før fabrikken var driftsklar. De hadde antakelig utført arbeid med klargjøring av maskinene, kanskje i forbindelse med rørføringer for damp. 
Den 18. november 1874 utbetales 50 spd. til "Architægt Aschenbach paa Gjøvik paa hans Tilkommende for Byggearbeide i Rødfossen." Tre uker seinere får han en "Rest" på 26 spd. J. C. C. Aschenbach var ikke arkitekt, men byggmester. Likevel er det grunn til å tro at når Jens Bjerknes kaller ham arkitekt så kan det skyldes at Aschenbach har gjort tegnings- og planleggingsarbeide i forbindelse med byggingen.

Johan Saugstad (f. 1826) var verksmester ved fyrstikkfabrikken etter idriftsettelsen. Han dukker opp i regnskapsboka første gang i oktober 1874. Da var muligens byggingen av fabrikkbygningen kommet så langt at maskiner og innredning stod for tur. Johan Saugstad var fra Fåberg og altså sambygding med Jens Bjerknes. Det er derfor nokså sikkert at han ble håndplukket til jobben av Bjerknes. Regnskapsboka viser at Saugstad har stor tillit, og etter at Collin blir borte våren 1875 er det Saugstad som tar over den praktiske administrering av arbeidene. 31. august 1875 får ”J. Saugstad udbetalt sin Maaneds Løn for August", og den var på 26 spd. I 1875 var det 26 hverdager i august, og han hadde derfor 1 spd om dagen, 25-50\% mer enn byggearbeiderne.

\section{SMEDSHAMMER}

Samtidig med at fyrstikkfabrikken var under oppføring gikk de "gamle" deler det som var Rødfos Værk sin gang. Det var mølla som Hans Møller drev samtidig som han hadde plassen Persvea. Og det var saga som Andreas Sagmester stod for. Hans Møller betalte 3 spd. $\mathrm{i}$ året for Persveen. Det var også to plasser Rødfossengen, - Kristian Engen betalte 8 spd. i avgift, Andreas Engen 2 spd. 2 ort og 12 skilling.
Men den største aktiviteten var knyttet til "Rødfos Liafabrik" på Smedshammer. Smedshammer var utskilt fra Raufoss gård i 1859 da svensken Ole Erikson anla ei stor ljåsmie. Et vasshjul drev tre vasshammere i smiebygningen.

I regnskapsboka finner vi Smedshammer nevnt første gang 14. oktober 1873: "Laant Smedshammer 1.500 spd." Det som skjedde her var at Rødfos Værk kjøpte tilbake Smedshammereiendommen fra Ole Erikson.

Jens Bjerknes har så den 14. november 3 skilling i utgift på ”Porto for et Brev til Ljåsmed P. A. Nordal.” Peder A. Nordal kom til Raufoss, han var fra Sverige i likhet med Ole Erikson. Det var plass til to familier i Smedshammer og Frantz C. Mjøberg, også svenske, ble den andre smeden.

Den 28. april 1874 ser vi at Jens Bjerknes skriver til August Lind et Co. i Stockholm og bestiller stål for $25 \mathrm{spd}$. Ellers er det vanskelig å få helt oversikt over omfanget av ljåproduksjonen ettersom en stor del av omsetningen ser ut til å ha foregått i et mellomregnskap med kjøpmann Skattum på Gjøvik. Den 3. juli 1874 er det bokført 4 spd. 2 ort 20 skilling for "1 Tylt Lier" med fradrag av 5\% som er solgt til J. Sørgendal. Dette gir 2 ort $(=2 / 5$ spd) pr. ljåblad.

1. juni 1875 reiser Jens Bjerknes til Kristiania og den 14 . juni har han notert i regnskapsboka: "Til Kjøbmand F. Lønseth Grendsen i Kristiania 40 a 50 Tylter Liaer hvoraf omtrent 1/3 Deel av 4 1/2 (kvart)Al. Resten 5 q og 1 a 2 Tylter 4 q. Liaerne leveres paa samme Betingelse til Lønseth som til Skattum med 5\%." Ljåene ble altså levert i tre ulike lengder regnet i kvarte alen. Bjerknes skriver videre at han direkte leverte 1 tylt, altså 12 stk. 5 kvart-alen ljåer. En bestilling på 600 ljåer var ikke dårlig! 
I juni 1875 ble det sendt ny bestilling til A. Lind i Stockholm på "2 Kasser Staal", igjen for $25 \mathrm{spd}$.

En annen viktig bestanddel i smievirksomheten var kull. Den 23. november 1874 kan vi lese: "Kjøbt af J. Roset med flere 50 Lacter Kul leveret til Rødfos Liafabrik for 2 spd. 1 ort pr. Lact. Kullerne skal leveres inden 14de April 1875 saaledes: af J. Roset 17 Lacter, L. L. Roset 15 Lacter, Lars Chr. Roset 15 Lacter og af Johanes S. Roset 8 Lacter, tils. 50 Lacter." En lakt kull var et kubikkmål som tilsvarte omlag 3x3x1 alen, nokså akkurat 2 kubikkmeter. Om disse leveransene skjedde på denne måten ser vi ikke i regnskapsboka.

Lars L. Roseth får imidlertid påbetalt 20 spd. for kull den 17. april 1875. Den 28. april leverer han 12 1/2 lakt, Anton Andreassen Sørlien 3 1/2 lakt og den 5. mai leverer Lars L. Roseth ytterligere vel 17 lakter.

Den 30. juni 1875 får Ole Lerudeie ei daglønn for å ha skjeftet og dreiet "Slibestenene" ved Smedshammersmia. Samtidig har Johan Saugstad tatt imot 4 spd. 2 ort, 12 skilling for "Slibning af 750 Knivblader a 3 ort pr. 100". Ljåproduksjonen krevde naturlig nok slipesteiner, som sannsynligvis også var drevet av vasshjulet. Og den store knivproduksjonen i V. Toten kunne dra nytte av dette anlegget. Ferdiggjøringen av knivbladene krevde også enda mer sliping enn ljåbladene. I juli som var neste måned kunne Saugstad ta inn nesten 8 spd. for "Knivbladslibning." Det vil si omkring 1.300 knivblader.

\section{AKSJOnÆREne}

Som nevnt foran var tyngdepunktet i eierinteressene utenfor distriktet. Mens Jens Bjerknes koordinerte aktiviteten på Raufoss og oppbyggingen av den nye fabrikken, er det overrettssakfører Wilhelm Faye-Hansen som

synes å koordinere interessene til investorene i Kristiania. Han oversender hver måned et større beløp til Bjerknes, og det er i hovedsak disponeringen av disse pengene regnskapsboka viser. I alt sender Faye-Hansen 22.143 spd. til Bjerknes i løpet av de to årene.

Men Bjerknes tok imot innbetalingen av aksjekapitalen fra de lokale aksjeeierne direkte. De ser ut til å ha innbetalt sine andeler i 5 terminer, totalt 1.600 spd. Kjøpmann Skattum på Gjøvik skjøt inn 100 spd, sivilingeniør Adam Collin 500 spd, David Øfstaas, bonde på Bøverbru, 200 spd, Martin Morterud som var landhandler, 200 spd., O. C. Præstesæter, bonde på Reinsvoll 20 spd., Johan Braastad, Vardal, 100 spd., Peder Adolf Lie, gardbruker på Lie, 100 spd. og til sist Jens Bjerknes sjøl som hadde aksjer for 200 spd. Dette var det som var innbetalt i 5 terminer. Hvis innbetaling skjedde også etter 1. sept. 1875 , var den lokale kapital større.

Hadde Bjerknes for mange penger liggende, satte han de inn på Gjøvik, enten i Holmen Brenneri eller hos kjøpmann Skattum. Dette ga 4\% innskuddsrente. Var kassa helt tom, måtte Bjerknes låne. Den 13. mai 1875 "Modtaget et Laan af O. C. Præstesæter" på 800 spd., og den 7. juni låner han 200 spd. av Martin Indahl og samme beløp av Ole F. Flikkeshaug. For lånene er det 5\% rente. Først i 1876 innledet Rødfos Værk kontakt med Totens Sparebank, da ved å låne 700 spd. Da var imidlertid O. C. Præstesæter blitt bankkasserer, så det som skjedde var vel kanskje at restbeløpet på de 800 spd. han hadde lånt ut ble gjort om til lån i sparebanken.

For sitt arbeid med administreringen av oppbyggingen av fyrstikk-fabrikken mottok Bjerknes 300 spd. som "det Tilkommende Honorar". De siste 50 spd. tok han ut 31 . 
10 august 1875, dagen før han overlot fabrikken til den nye bestyreren.

\section{"Pigerne fra Jølsen"}

Sommeren 1875 begynte fabrikkanlegget å ta form. Men hvordan ville det være å starte opp en så spesiell industriproduksjon i et område der de færreste noensinne hadde sett en fabrikk?

Bjerknes sjøl måtte også lære om produksjonen og skaffe seg kontakter. Den 14. juni 1875 skriver han i regnskapsboka: "Udlagt paa en Reise til Kristiania om Nittedalen og Enebak for Diet i 7 Dage og Skyds." Utgiftene var på 12 spd. og 3 ort. Nitedals Tændstikfabrik som Bjerknes besøkte var en av landets største fyrstikkfabrikker. I Enebakk lå proprietær Holm Jølsens fyrstikkfabrikk.

En måned seinere er Bjerknes igjen på farten, og han bokfører 11 spd. 2 ort og 8 sk. den 19. juli som "Udlæg paa en Reise til Kristiania og 2 Reiser til Jølsens Fyrstikfabrik."

Resultatene fra denne reisevirksomheten viser seg 10 dager seinere da Bjerknes utbetalte 3 spd. til Amund Olsen og "Pigerne fra Jølsen paa Arbeide.”

Først i august utbetales det så 21 spd. til H. Jølsen før "hans Udlæg til de hidsendte Arbeidere." Det blir også utbetalt nær 3 spd. i slutten av august til E. Forberg "for Nattelogi m.m." for arbeiderne fra Jølsen.

Hvorfor så stor vekt på å få tak i disse "Pigerne fra Jølsen"? Jo, størstedelen av de ansatte i en slik fyrstikkfabrikk var kvinner. Og det var på pakkeriet de var sysselsatt. $\AA$ få til en effektiv drift her var en absolutt nødvendighet. Antakelig kunne heller ikke noen av mennene som satte igang fabrikken å pakke fyrstikker!

Den 31. desember 1875 ble det holdt fol- ketelling. Og der ser vi da også hvem "Pigerne fra Jølsen" var. I ei av leilighetene i arbeiderboligene bodde nemlig de tre ugifte jentene Johanne Marie Johannessen, 19 år, Gunhild Amundsen, 24 år og Karen Bergithe Amundsen, 19 år. I tillegg var Olaus Edvartsen, 19 år, også kommet til Raufoss fra Enebakk. De andre arbeiderne var født på Toten, Hedemarken og i Valdres.

\section{OsPEKJØP}

Ved siden av tilgangen på arbeidskraft, og vannkraften i Raufossen, var ospevirke den viktigste lokale ressurs for fabrikkdriften. Allerede med en gang byggingen av fabrikken starter i 1873 er Jens Bjerknes igang med å sikre seg nok osp. Den 20. oktober 1873 leser vi: "Betalt Peder O. Steffensrud for den ifølge Kjøbekontragt af 15de Kjøbte Asp 63 spd."

Dagen etter fører Bjerknes 1 ort som "Udlagt paa en reise i Anledning Indkjøb af Asp i 2 Dage." Og samme dag påbetaler han $5 \mathrm{da}$ ler hver til Kristian Larsen Hexum og Peder C. Hexum for osp.

Utover i november og desember 1873 gjør Bjerknes flere slike avtaler med forskuddsbetaling. Likeens vinteren 1874, da for levering høsten 1874.

Ospa ble levert i 4 eller 5 aleners lengder, målt i favner. 17. april 1875 leverer Ole Amundsen Bjugstad "1/2 Favn 5 Al. Asp a 3 ort 12 sk." For dette fikk han 7 spd. Det viser at det ble betalt 84 skilling pr. kvart alen av favnen. Og en pris på 14 spd. for en favn var en god pris.

Ettersom ospevirket levert i 1874 bare ble liggende, og det ble gjort nye innkjøp i 1875 , må det ha vært en anselig mengde osp på lager da produksjonen startet høsten 1875. Men 
det skulle også til, - fra ospeveden ble det laget både stikker og fyrstikkesker.

\section{FABRIKKEN ER FERDIG}

I månedsskiftet juli-august 1875 begynner brikkene å falle på plass. Fabrikkbygningen er ferdig, råvarene ligger der, spesialarbeiderne er ankommet og arbeiderboligene er i ferd med å bli klare.

Den 29. juli er noe på gang, for da kjøper Bjerknes 100 frimerker, 2 ris med papir og betaler 2 spd. 3 ort til "Bogtrykker Christen for Trykning efter Regning". Boktrykkeren var Jens Chr. Christensen (f. 1827) som siden 1860 utga "Kristians Amtstidende" på Gjøvik. Hva Bjerknes sendte ut vet vi ikke, men det hadde nok sikkert noe å gjøre med den nær forestående oppstarten av fabrikken.

Den 4. august får lensmann Bratli betaling for to takstforretninger, - en over fabrikkbygningen med tilstøtende materialbod i bindingsverk, og en over maskinene. Dette var i Norges Brandkasse. De andre bygningene, altså arbeiderboligene og gardhusa, ble forsikret i Toten og Vardals Brandkasse ved takst samme dag.

Tre uker seinere betaler Bjerknes "for et Avertissement" i avisene Almuevennen, Verdens Gang og Morgenposten. Han betaler også 16 skilling til "Lensmand Bratli for en Bekjendtgjørelse fra Kirkebakken”. Dette siste var altså ved Aas kirke, og vi må regne med at det var samme kunngjøring i avisene som det lensmannen offentliggjorde fra kirkebakken. Kanskje var det meldingen om at fabrikken nå skulle starte opp. Det er jo mulig å finne ut dette ved å gå tilbake til avisårgangene fra 1875. At Bjerknes ikke averterte i lokalavisene i Oppland, men brukte lensmannen til å kunngjøre, knytter seg sjølsagt til det faktum at svært få den gang holdt disse avisene.

Den 20. august 1875 utbetaler Bjerknes 3 ort 16 skilling til "Madame Saugstad for Kost til en Mekkanikker i 1 1/2 dag og for inkjøbt Sæbe m.m." Nå ble antakelig dampmaskineriet igangkjørt, og den 31. august avslutter Berknes føringen av regnskapsboka.

Etter dette er det bare to posteringer; den 8. og den 15. september, begge lyder "Udbetalt Lange", og det var tilsammen ca. 260 spd. Lange det var Otto Wincent Lange (f. 1848) opprinnelig fra Tromsø, som nå vil vi tro med oppstart den 1. september 1875 var ansatt som bestyrer for fyrstikkfabrikken. To års byggevirksomhet og forberedelser var over, og styreformann Jens Bjerknes kunne overlate fabrikken med daglig drift og regnskapsføring til Otto W. Lange.

Note

- Texten hämtad ur: TOTN. Årbok 1988, s. 107117 (Gjøvik 1988). 